Saudi Journal of Oral and Dental Research

Abbreviated Key Title: Saudi J Oral Dent Res

ISSN 2518-1300 (Print) |ISSN 2518-1297 (Online)

Scholars Middle East Publishers, Dubai, United Arab Emirates

Journal homepage: https://saudijournals.com/sjodr

\title{
Development of a Dental Nutrition Attitudes, Beliefs, and Behaviors Scale for Low-income Women
}

\author{
Mahsa Babaei, Jeanne Freeland-Graves ${ }^{*}$, Prageet K. Sachdev \\ T.S Painter Hall 3.18, The University of Texas at Austin, Department of Nutritional Sciences, College of Natural Sciences 103 W 24th St A2703, \\ Austin, Texas 78712, United States
}

DOI: $10.36348 /$ sjodr.2020.v05i03.005

| Received: 03.03.2020 | Accepted: 12.03.2020 | Published: 18.03.2020

*Corresponding author: Jeanne Freeland-Graves

Abstract

Objective: Develop a valid and reliable scale to assess the attitudes, beliefs, and behaviors related to eating foods associated with the periodontal disease among low-income women in Texas. Study Design: This is a cross-sectional study. Methods: The study was conducted with 150 low-income women ages 18-50 years, residing in Central Texas. A 21-item Dental Nutrition Attitudes, Beliefs, and Behaviors Scale was developed. Content validity was assessed by a panel of experts. Construct validity was determined via Exploratory Factor Analysis; internal consistency of the scale was measured by Cronbach's alpha. Results: The internal consistency for the final scale was 0.802 , and the test-retest reliability was 0.99. Factor analysis generated three factors: Attitudes, Beliefs, and Behaviors, with an explained variance of 42.38. Conclusions: These results confirmed the validity and reliability of the new dental scale. This instrument may aid in the assessment of attitudes, beliefs, and behaviors regarding eating foods associated with periodontal disease in low-income women.

Keywords: attitudes; beliefs; behaviors; validity; reliability.

Copyright @ 2020: This is an open-access article distributed under the terms of the Creative Commons Attribution license which permits unrestricted use, distribution, and reproduction in any medium for non-commercial use (NonCommercial, or CC-BY-NC) provided the original author and source are credited.

\section{INTRODUCTION}

Periodontal disease is an inflammatory disease involving gingival tissue, alveolar bone, and periodontal ligaments [1]. According to the 2016 Centers for Disease Control and Prevention (CDC), periodontitis is present in $50 \%$ of Americans, in ages 30 years and older [2, 3]. This high prevalence is of concern as evidence indicates periodontal disease is associated with systemic conditions such as diabetes, cardiovascular disease, osteoporosis, and adverse pregnancy outcomes $[3,4]$. A higher prevalence of the periodontal disease has been observed in those living below the federal poverty level (income $\leq 250 \%)(65.4 \%)$, with less than a high school education $(66.9 \%)$ and smokers (64.2\%) [2].

This study will focus on women with low socioeconomic status (SES). Women were chosen as tey exhibit an increased risk for periodontal disease because of the hormonal fluctuations during puberty, menstruation, pregnancy, and menopause. Also, oral contraceptive use has been reported to be linked to gingival inflammation and bleeding [5]. It has been documented that low-income women have less healthy diets than those with higher incomes [6]. In many households, women are primarily responsible for providing food and may transfer attitudes and dietary behaviors from their childhood [7, 8] Subsequently, these attitudes, beliefs, and behaviors may influence their food choices and the diet quality of the overall household.

The current research will focus on certain foods, including saturated fatty acids, added sugars, whole grains, fruits and vegetables, and dairy, that affect the risk of periodontal disease. Saturated fatty acids and added sugars are both detrimental for oral health, as these may promote inflammation [9-13]. In Japanese individuals who were non-smokers, a high intake of saturated fatty acids was significantly linked to a greater number of periodontal disease events. In an NHANES study of young adults, middle and upper tertiles of added sugar consumption were associated with periodontal disease [14]. In contrast, whole grain and fiber intakes are considered protective foods, as they improve insulin sensitivity and decrease the risk of periodontitis [15]. Dairy foods also have been reported to be beneficial for periodontal disease due to their Vitamin D and calcium content. These nutrients impede alveolar bone loss, with enhancement in retention of the natural dentition [16]. Those in the highest quintile of 
dairy intake in an NHANES study were $20 \%$ less likely to have periodontitis than those from the lowest quintile $[14,17]$.

The current research will focus on the attitudes and beliefs that affect behaviors regarding the consumption of these foods that affect periodontal disease. Attitudes are assessments that one makes about objects, ideas and other people, while beliefs are the assumptions that are built based on past experiences. Numerous health behavior theories emphasize the importance of identifying and modifying attitudes and beliefs in order to transform behaviors [18]. The Theory of Reasoned Action posits that an individual's behavior is a function of prexisting attitudes [19]. The Health Belief Model focuses on the interplay between individual beliefs and attitudes about disease conditions, which may explain and predict healthrelated behaviors [20]. Finally, the Theory of Planned Bnumerouehavior [21] suggest that behaviors are influenced by attitudes, such as how likely a behavior will have the expected outcome [22]. Constructs from these theories will be utilized to explain health behaviors and intentions regarding consumption of foods that are related to periodontal disease.

A scale will be developed that assesses constructs to improve diets to decrease the risk of periodontal disease. Previously, an improvement in attitudes and beliefs about nutrition encouraged dietary behaviors that promote better health [23-25]. The goal of this research is to develop a validated and reliable questionnaire to assess nutrition-related attitudes, beliefs, and behaviors regarding foods that influence periodontal disease in a low-income women population.

\section{METHODS \\ Study design}

The process of study design and scale development and validation is shown in figure 1 . This is a cross-sectional study of low-income women who were administered a revised demographic survey and a Dental Nutrition Attitudes, Beliefs, and Behavior Scale at one visit. A subsample of 40 women repeated the scale at a second visit, two weeks later, to determine test-retest reliability. Several questions regarding smoking, alcohol, and drug use were added to the original demographic questionnaire.

\section{Sampling Method}

The women were recruited from low-income housing units and recreation centers. The housing was supported by the Foundation Communities (Austin, Texas), an organization that provides affordable housing for low-income individuals with an income $\leq 50$ $\%$ of the Median Family Income $(\$ 41,280$ for a family of four in 2018) [26] set by the Texas Department of Housing and Community Affairs [27]. Since the 2018 U.S. Federal Poverty Level (FPL) was $\$ 25,750$, those with an income $<200 \%$ of the FPL (annual income $\$ 51,500$ ) were categorized as low-income [27]. Publicity about the study was generated by flyers that were left at doorsteps of apartments, community centers, and recreation centers of the low-income housing units. These flyers covered details and inclusions of study, as well as the contact information of the researchers and time and location of the research meeting in the community centers.

\section{Participants}

Participants were women with an income of less than $250 \%$ of the Federal Poverty Level, ages 18 50 , and who had received a dental treatment within the last five years. Exclusion criteria were factors that increase the risk of periodontal disease including pregnancy, smoking, and systemic illness. Also, enrollment in graduate school was an exclusion criteria as the more educated might have a greater knowledge of nutrition that might bias results. The risks and benefits of the study were explained, and a verbal and written informed consent was obtained. The Institutional Review Board at the University of Texas at Austin approved the complete research. A \$5 gift card was provided to the participants who completed the demographics and the Dental Nutrition Attitudes, Beliefs, and Behavior Scale. The study was undertaken with the understanding and written consent of each subject in accordance with the World Medical Association Declaration of Helsinki and the additional requirements.

\section{Scale Development Method}

Numerous theories of individual level health behaviors emphasize relationships between attitudes and beliefs that drive a behavior $[19,28]$. These include the Theory of Reasoned Action (TRA), Health Belief Model (HBM), and Theory of Planned Behavior (TPB). In the context of this research, the present instrument focused primarily on constructs of attitudes and beliefs, and behaviors regarding eating foods that have been associated with periodontal disease. These include added sugars [29], inflammatory foods [11], fruits and vegetables [30], and dairy [31]. Although the constructs of attitudes and beliefs do not explain all variability in human behavior, these crucial determinants have been utilized to understand health promotion interventions [32-37].

A literature search explored dietary factors and foods that influenced periodontal disease. Items were generated to create an instrument to measure attitudes, beliefs, and behaviors regarding eating foods that are associated with periodontal disease. An initial scale was created, and content, readability, and item difficulty were assessed by a panel of seven nutritionists (all were Registered Dietitians) and three dentists (all held Doctorate of Dental Surgery). Then a focus group of six low-income women evaluated the readability and comprehension of the scale. Feedback from the panel of nutritionists and dentists and focus group was utilized to 
revise items to create the final version of the scale. The questionnaire was available in English and Spanish. A panel of two bilingual graduate students translated the survey into Spanish. Then, both Spanish translations were back translated into English and compared to the original English scale for any inconsistencies [38].

\section{Item generation}

A tentative scale composed of 43 items was generated initially based on a literature review of foods that affect the prevalence and severity of periodontal diseases. It included observational, cross-sectional, prospective, and case-control studies that evaluated relationships between diet and periodontal disease. The literature search focused on four food groups associated with periodontal disease: added sugars [14]; proinflammatory foods [10]; fruits and vegetables [30]; and dairy [31]. Added sugars may induce inflammation and oxidative stress as demonstrated in periodontal disease [39]. Other pro- inflammatory foods (refined carbohydrates and saturated fatty acids) also may drive oxidative stress in cells, which increases the plasma concentration of pro- inflammatory cytokines and intensifies periodontal inflammation [40]. In contrast, fruits and vegetables have a positive effect on periodontal health due to their abundant vitamin $\mathrm{C}$ content. This vitamin has been linked to the restoration of collagen, a protein that maintains the integrity of the tooth attachment ligaments to the bone [41]. Dairy products also are beneficial, as their high calcium, vitamin $\mathrm{D}$, and phosphorus content may be linked to the prevention of alveolar bone loss [17]. Finally, salivary calcium and phosphate may prevent bacterial biofilm formation which promotes periodontal disease [42].

The questions were divided into three groups: attitudes, beliefs, and behaviors. The attitudes subscale $(\mathrm{N}=7)$ consisted of questions regarding attitudes about high carbohydrate and high-added sugar foods, solid fats, fruits and vegetables, milk, and the importance of dental visits regarding periodontal disease. The beliefs subscale $(\mathrm{N}=7)$ explored beliefs about the consumption of high-added sugars products, candy/chocolate, saturated and unsaturated fatty acids, fruits and vegetables, and dairy foods in preventing periodontal disease. The third subscale $(\mathrm{N}=7)$, behaviors, included questions about consumption of added sugars, proinflammatory-inducing foods, fruits, and vegetables, as well as food labeling, brushing, and flossing.

Questions were constructed on a sixth-grade reading level and designed as a 5 point Likert scale. Responses to items were rated as strongly disagree, disagree, neutral, agree, and strongly agree. Belief items had possible answers of very important, important, neutral, less important or not important. Each item scored from 1 to 5 , such that 5 represented a strong attitude, belief, and behavior toward healthy foods and dental health, and a 1 denoted weak. To avoid response biases associated with multi-item scales that are phrased in a single direction, the questionnaire included four reverse coded items. Responses to each item within a subscale were summed to calculate a subscale score. Scores obtained from this scale were added to compute final attitude and belief scores.

\section{STATISTICAL ANALYSIS}

All statistical analysis and data management was performed using Predictive Analytics Software Statistics (SPSS version 18.0, SPSS Inc., Chicago, IL, 2009). Statistical significance for all tests was set at the $\mathrm{p}<0.05$ levels.

Items were removed if these showed low variability in responses or exhibited low correlation with the scale. The internal consistency was measured by the calculation of Cronbach's Alpha coefficient, a coefficient of reliability, which shows how closely sets of items are associated as a group [43]. The value of 0.7 and above are acceptable for each theoretical construct on the final questionnaire [43]. The reliability of the scale was determined by a paired sample t-test, measured at two different time points [44]. Test re-test reliability of the questionnaire was established by testing the same questionnaires 2 weeks later in a subsample of 40 low-income people.

Since the items in the instrument were ordinal in nature, a factor analysis based on a polychoric correlation matrix was conducted using M-plus software (version 8.1). Exploratory factor analysis with varimax rotation, using weighted least squares with means and variance estimator, was conducted to reduce and place items in appropriate domains. Factor loadings $>0.3$ were deemed as meaningful and items greater than this criterion were retained in the construct [45]. The Kaiser-Meyer-Olkin test was used to imply the proportion of variance in variables that may be caused by underlying factors. The cut off value was $\geq 0.7$ indicating that sampling is adequate. Bartlett's test of sphericity was calculated to establish that the correlation matrix is an identity matrix [46]. Bartlett's test implies that the variables are unrelated and unsuitable for structure detection.

\section{RESULTS}

\section{Demographic characteristics}

A convenience sample of 150 women was recruited from low-income households. This number is close to the 5:1 ratio rule (5 participants per question) for Exploratory Factor Analysis [47]. The women had an average age of $36.31 \pm 9.43$ yrs., with a range of 18 to 50. Participants were more likely to be Hispanic, had a high school degree, and an annual household income of less than $\$ 25,000$ (Table 1).

\section{Item Trimming}

Initially, a 43-item questionnaire was created based on the search of the literature and then reviewed 
by an expert panel. Consequently, five questions not compatible with the theoretical construct were removed, as well as two others that had biased connotations in attitudes towards foods that promoted periodontal disease. Then the questionnaire was pretested in a focus group of six low-income women for its readability and comprehension. This step eliminated another two items. Exploratory factor analysis further removed 14 questions, as these items loaded the least $(<.30)$ on their respective factor or cross-loaded substantially across factors. The final validated questionnaire consisted of 21 items.

\section{Construct validity}

The primary structure of the scale contained 35 items retained for factor analysis. Items 1-10 were designed as "attitudes," 11-24 contained "beliefs," and 25-35 comprised "behaviors." The Kaiser-Meyer-Olkin was 0.72 , and Bartlett's sphericity was significant $(\chi 2=$ 969.371, $\mathrm{p}<0.0001)$. This Bartlett value illustrated that the sample was appropriate for factor analysis. In the exploratory factor analysis, a higher extraction communality value shows the greater influence of the corresponding item. Thus, seven questions were removed because their extraction communality were $<0.3$; the final communalities ranged from 0.3 to 0.802 . Factor analysis generated five factors, with an explained variance of $45.03 \%$. Also, among 35 items, seven questions did not load on expected factors and were deleted. Thus, the final scale contained 21 items. In the second run of factor analysis with varimax rotation, three factors with Eigenvalues of greater than 1.5 were identified. The cumulative explained variance rate of 21 items was $42.38 \%$. These factors were characterized as: attitudes, beliefs, and behaviors. The number of questions in each subscale, item means, variance, minimum, and maximum of subscale scores are presented in Table 2. Factor 1 accounted for $10.69 \%$ of the variance and contained seven items that focused on attitudes about the diet that affected the periodontal disease. An example of an attitude was, "If I eat foods with added sugars, I may increase my risk of gum disease." Factor 2 referred to nutritional beliefs toward periodontal disease. It accounted for $9.36 \%$ of the variance and consisted of seven items. A sample of a belief was, "How important/not important is it to consume salmon, tuna, and sardine to prevent gum disease?." Factor 3 accounted for $22.32 \%$ of the variance and focused on seven items that determined behaviors regarding periodontal disease. The typical question was, "I usually eat vegetables with my meals." The average loading for attitudes items was 0.63; beliefs, 0.52; and behaviors, 0.67. Item means and standard deviations are presented in Table 3.

\section{Internal consistency}

The internal consistency coefficients of the 21-item scale were 0.802 . The Cronbach's alpha of different constructs of the scale was: attitude 0.78 , belief 0.62 , and Behavior 0.77 (Table 2).

\section{Test-retest reliability}

According to the results of the re-test performed by 40 participants 2 weeks later, the reliability, as measured by Pearson correlation tests for attitudes, beliefs, and behavior were 0.98, 0.97, and 0.99 , respectively $(\mathrm{p}<0.001)$. These results indicate that the scale had excellent stability over time (Table 2 ).

Table-1: Socio-demographic characteristics of a sample of low-income women $(n=150)$ from Central Texas enrolled in a validation of Dental Nutrition Attitudes, Beliefs, and Behavior Scale

\begin{tabular}{|c|c|}
\hline Characteristics & $\mathbf{N}(\%)$ \\
\hline Ages (yr) & \\
\hline $18-25$ & $23(15.3)$ \\
\hline $25-35$ & $42(28)$ \\
\hline $35-50$ & $85(56.6)$ \\
\hline Race/ethnicity & $81(54.1)$ \\
\hline Hispanic & $32(21.3)$ \\
\hline White & $20(13.3)$ \\
\hline African-American & $17(11.3)$ \\
\hline Other & \\
\hline Annual income (\$) & $98(65.3)$ \\
\hline$<25,000$ & $19(12.7)$ \\
\hline $25,000-34,999$ & $23(15.4)$ \\
\hline $35,000-49,999$ & $10(6.6)$ \\
\hline $50,000-60,000$ & \\
\hline Education level & $39(26.0)$ \\
\hline Junior high school and less & $61(40.6)$ \\
\hline High school & $46(30.8)$ \\
\hline College or university graduate & $4(2.6)$ \\
\hline Graduate professional training &
\end{tabular}

Table-2: Item score means, variance, minimum, maximum, and subscales reliability of Dental Nutrition Attitudes, Beliefs, and Behaviors

\begin{tabular}{|l|c|c|c|c|c|c|c|}
\hline Constructs & $\mathbf{N}$ & $\begin{array}{c}\text { Score } \\
\text { Means } \\
\left.\mathbf{S D}^{\mathbf{a}}\right)\end{array}$ & Variance & Minimum & Maximum & $\begin{array}{c}\text { Cronbach's } \\
\text { alpha } \\
\text { coefficient }\end{array}$ & $\begin{array}{l}\text { Test-retest } \\
\text { reliability }^{\mathbf{b}}\left(\text { Pvalue }^{\mathbf{c}}\right)\end{array}$ \\
\hline Attitudes & 7 & $3.39(1.25)$ & 1.53 & 2.97 & 3.99 & 0.78 & $0.98(0.001)$ \\
\hline Beliefs & 7 & $3.95(1.23)$ & 1.28 & 3.74 & 4.39 & 0.62 & $0.97(0.001)$ \\
\hline Behaviors & 7 & $3.71(1.22)$ & 1.46 & 3.18 & 4.04 & 0.77 & $0.99(0.001)$ \\
\hline
\end{tabular}

\section{${ }^{\mathrm{a}}$ Standard deviation}

${ }^{\mathrm{b}}$ Pearson correlations coefficient between item scores $(\mathrm{n}=36)$

${ }^{\mathrm{c}}$ Statistically significant at $\mathrm{p}<0.01$ 
Table-3: Factor loading matrix of the 21-item scale of Dental Nutrition Attitudes, Beliefs

\begin{tabular}{|c|c|c|c|c|}
\hline \multirow[t]{2}{*}{ Items } & \multirow{2}{*}{ Mean $\left(\right.$ SD $\left.^{\mathbf{a}}\right)$} & \multicolumn{3}{|c|}{ Factor loadings } \\
\hline & & Attitudes & Beliefs & Behaviors \\
\hline 1 & $3.41(1.391)$ & 0.539 & 0.002 & 0.112 \\
\hline 2 & $3.53(1.299)$ & 0.578 & -0.007 & 0.268 \\
\hline 3 & $3.04(1.203)$ & 0.699 & 0.085 & 0.171 \\
\hline 4 & $3.08(1.173)$ & 0.753 & 0.038 & 0.035 \\
\hline 5 & $2.97(1.217)$ & 0.703 & -0.023 & 0.170 \\
\hline 6 & $3.69(1.231)$ & 0.627 & 0.372 & 0.090 \\
\hline 7 & $3.99(1.147)$ & 0.577 & 0.116 & -0.043 \\
\hline 8 & $3.83(1.174)$ & 0.194 & 0.413 & -0.002 \\
\hline 9 & $3.99(1.129)$ & 0.006 & 0.686 & 0.152 \\
\hline 10 & $4.41(0.943)$ & 0.137 & 0.610 & -0.013 \\
\hline 11 & $3.89(1.027)$ & -0.109 & 0.729 & 0.029 \\
\hline 12 & $3.90(1.191)$ & -0.053 & 0.609 & 0.221 \\
\hline 13 & $3.75(1.061)$ & -0.003 & 0.330 & 0.240 \\
\hline 14 & $3.99(1.336)$ & 0.070 & 0.303 & 0.000 \\
\hline 15 & $3.53(1.422)$ & 0.249 & -0.192 & 0.328 \\
\hline 16 & $3.81(1.294)$ & 0.068 & 0.098 & 0.549 \\
\hline 17 & $3.19(1.255)$ & 0.190 & 0.284 & 0.467 \\
\hline 18 & $3.71(1.095)$ & 0.110 & 0.075 & 0.808 \\
\hline 19 & $4.05(0.992)$ & 0.178 & 0.087 & 0.815 \\
\hline 20 & $3.91(1.155)$ & 0.230 & 0.094 & 0.788 \\
\hline 21 & $3.84(1.210)$ & -0.025 & 0.069 & 0.669 \\
\hline
\end{tabular}

And Behaviors ${ }^{\text {a Standard deviation }}$

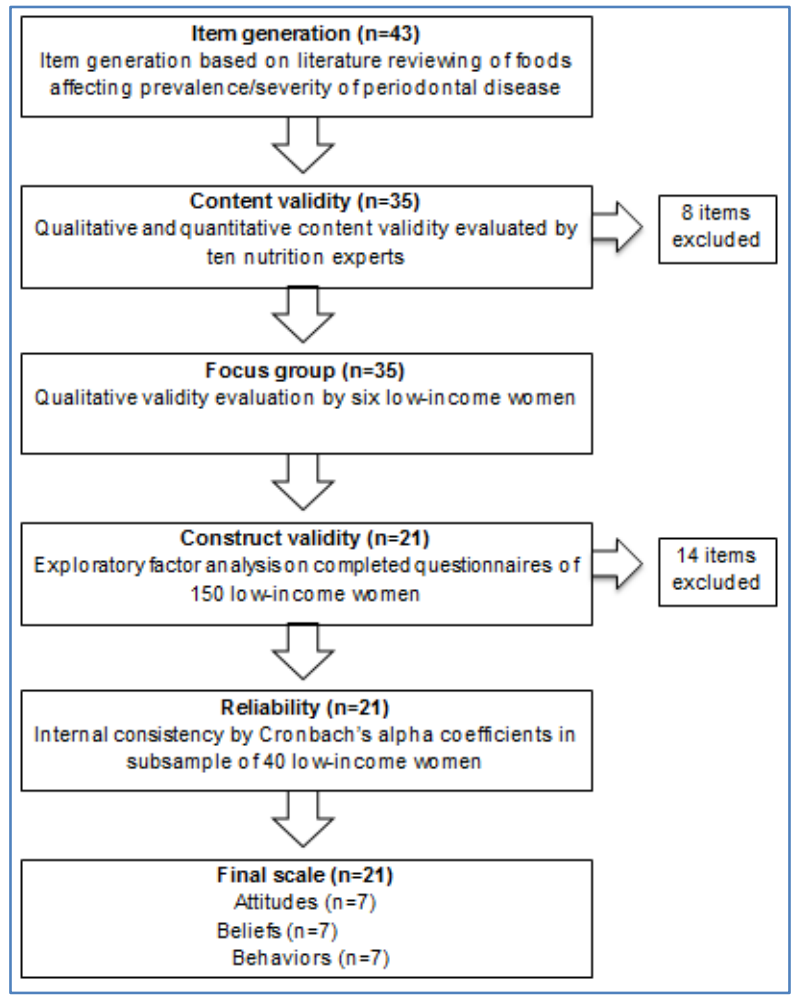

Fig-1: Process of instrument development; $n=$ number of questions

\section{DISCUSSION}

These results suggest that the Dental Nutrition Attitudes, Beliefs, and Behaviors Scale is a validated, reliable instrument designed to assess attitudes, beliefs, and behaviors about the consumption of foods associated with periodontal disease in low-income women. To date, this is the only study that has developed and assessed the psychometric properties of dental nutrition in a low-income population.

The items for the scale were chosen based on a literature review of the foods associated with periodontal disease. Previous studies have acknowledged the role of sugars in postprandial hyperglycemia, which produces a proinflammatory cascade that has been linked to periodontal disease [48]. The type of dietary fat also may affect the activation of inflammatory factors such as IL-6, TNF-a, and C reactive protein [9]. In contrast, fruits and vegetables are sources of vitamin $\mathrm{C}$, which is involved in the restoration of collagen, which maintains the integrity of the attachment ligaments [49]. Similarly, studies have documented that calcium intake from dairy is protective against periodontitis $[50,51]$.

This scale was developed based on a combination of constructs of attitudes, beliefs, and behaviors from the Theory of Reasoned Action (TRA), Health Belief Model (HBM), and Theory of Planned Behaviour (TPB). For example, in the Theory of Reasoned Action, attitudes are considered key determinants of a particular behavior. This theory suggests a strong correlation between attitudes and outcomes, such that if one believes that a certain behavior will lead to a desirable or favorable outcome, then one is more likely to have a positive attitude towards the behavior [19]. Additionally, the Health Belief Model is a psychosocial theory that refers to 
individuals' health-related behaviors based on their attitudes and beliefs [20]. Likewise, the Theory of Planned Behavior aims to justify and predict health behaviors by focusing on the attitudes and beliefs of individuals. It proposes that behavior is a function of prominent information or beliefs, relevant to the behavior. These beliefs are assumed to influence attitudes toward the behavior [22]. Each of the above individual level theories emphasizes the importance of associations among beliefs, attitudes, and behaviors or some subset of these [52-56].

It is proposed that an attitude toward an object may impact beliefs formed about an associated object [57]. Measurement of social-psychological constructs have been successful in predicting behaviors that incorporate a health-related outcome such as the risk of periodontal disease as described in the result [58].

This scale has good content validity, as indicated by the expert panel of nutritionists and dentists. It also had a suitable readability level for health-related materials between the $5^{\text {th }}$ and $6^{\text {th }}$-grade reading levels. The reliability of 0.802 for the final scale met the ideal range of $0.7-0.8$ for a Cronbach's alpha [59]. All subscales verified adequate test-retest reliability. Although it would be useful to measure concurrent validity, this was not possible because a reference gold standard instrument does not exist, which assesses nutrition attitudes, beliefs or behaviors regarding periodontal disease.

The scale in this paper is comparable to other questionnaires that assessed general beliefs and attitudes. In Italian adolescents, the internal reliabilities were 0.36 and 0.32 for subscales that measured beliefs and attitudes towards the consumption of sugar-free products [60]. In female university students in Brazil, a 25-item scale designed to measure disordered eating attitudes explained $54.3 \%$ of total variance [61]. The total reliable variance of the three subscales of the present research is somewhat lower $(45.03 \%)$, but, it is still considered reliable, as there were three, rather than five, factors. Finally, Allison et al. created an instrument assesing attitudes and beliefs toward people who are obese; it had an excellent alpha reliability $(0.80$ to 0.84 ). However, the total explained variance of the scale was less than the newly developed scale of this paper (42.38 vs 45.03).

In sum, Cronbach's alpha coefficients of this scale were similar to most questionnaires above. However, a low alpha coefficient was observed on the beliefs subscale, but this may have been due to a low number of questions. Nonetheless, the Pearson correlation coefficient indicated that the scale has adequate reliability and that the final three-factor solution proposed had good psychometric results. Thus, this questionnaire serves as a valid and reliable multidimensional tool to capture attitudes, beliefs, and behaviors regarding periodontal disease.

The advantages of the newly developed scale are that it is short, easy to administer and evaluate. It provides a quick assessment of the nutrition attitudes, beliefs and behaviors in low-income individuals. Also, it is designed at a 6th-grade reading level so that it can be used to measure knowledge in a low-income population.

\section{LIMITATIONS OF THE STUDY}

The sample size of 150 women is a limitation of this study, but smaller sample sizes have been considered valid in the other investigations [62, 63]. Also, the instrument was developed and validated in low-income women, and the majority were Hispanic. Thus, the generalizability of this instrument may be limited for other ethnic/racial groups. Ideally, future research should test this scale in larger, more diverse populations. About $7 \%$ of the participants were not born in the US, such that English may not have been their first language. However, the scale was presented in both English and Spanish. Additional studies by the authors will evaluate the associations between the attitudes, beliefs, and behaviors assessed from this new scale and the status of periodontal disease in low-income women. Although, the Exploratory Factor Analysis could have been followed by Confirmatory Factor Analysis; [64] This approach was limited by the relatively small sample size $(\mathrm{N}=150)$ of the study.

\section{CONCLUSION}

Women play a key role in providing healthy diets in their households as they shape healthy eating behaviors in their children. An understanding and improvement of nutritional attitudes, beliefs, and behaviors regarding periodontal disease may improve overall family health as well.

This research developed a validated and reliable instrument to assess attitudes, beliefs, and behaviors regarding eating foods that are associated with periodontal disease. The new scale can be utilized in dental public health education for periodontal diseases in low-income women.

\section{DECLARATION OF HELSINKI}

The risks and benefits of the study were explained, a verbal and written informed consent were obtained, and the Institutional Review Board at the University of Texas at Austin approved the informed consent. The Institutional Review Board at the University of Texas at Austin also approved the complete study. A $5 \$$ gift card was provided to the participants who completed the demographics and the Dental Nutrition Attitudes, Beliefs, and Behavior Scale. The research was undertaken with the understanding and written consent of each subject in accordance with 
the World Medical Association Declaration of Helsinki and the additional requirements.

\section{ACKNOWLEDGMENT}

The authors would like to acknowledge the Bess Heflin Centennial Professorship for the support this research study.

\section{SOURCE OF FUNDING}

The Bess Heflin Centennial Professorship

\section{CONFLICT OF INTEREST}

The authors state that they have no conflict of interest.

\section{REFERENCES}

1. Botero, J.E., Rösing, C.K., Duque, A., Jaramillo, A., Contreras, A. (2015). Periodontal disease in children and adolescents of Latin America. Periodontology, 2000, 67:34-57.

2. Eke, P., Zhang, X., Lu. H., Wei, L., ThorntonEvans, G., Greenlund, K., Holt, J., Croft, J. (2016). Predicting periodontitis at state and local levels in the United States. Journal of dental research, 95:515-522.

3. Kim, J., Amar, S. (2006). Periodontal disease and systemic conditions: a bidirectional relationship. Odontology, 94:10-21.

4. Nazir, M.A. (2017). Prevalence of periodontal disease, its association with systemic diseases and prevention. International journal of health sciences, 11:72-83.

5. Martelli, M.L., Brandi, M.L., Martelli, M., Nobili, P., Medico, E., Martelli F. (2017). Periodontal disease and women's health. Current medical research and opinion, 33:1005-1015.

6. Krebs-Smith, S.M., Cleveland, L.E., BallardBarbash, R., Cook, D.A., Kahle, L.L. (1997). Characterizing food intake patterns of American adults. The American journal of clinical nutrition, 65:1264S-1268S.

7. Inglis, V., Ball, K., Crawford, D. (2005). Why do women of low socioeconomic status have poorer dietary behaviours than women of higher socioeconomic status? A qualitative exploration. Appetite, 45:334-343.

8. Lupton, D: The heart of the meal. (2000). food preferences and habits among rural Australian couples. Sociology of Health \& Illness, 22:94-109.

9. Ramirez-Tortosa, M., Quiles, J., Battino, M., Granados, S., Morillo, J., Bompadre, S., Newman, H., Bullon, P. (2010). Periodontitis is associated with altered plasma fatty acids and cardiovascular risk markers. Nutrition, Metabolism and Cardiovascular Diseases, 20:133-139.

10. Iwasaki, M., Manz, M., Moynihan, P., Yoshihara, A., Muramatsu, K., Watanabe, R., Miyazaki, H. (2011). Relationship between saturated fatty acids and periodontal disease. Journal of dental research, 90:861-867.

11. Chapple, I.L. (2009). Potential mechanisms underpinning the nutritional modulation of periodontal inflammation. The Journal of the American Dental Association, 140:178-184.

12. Aeberli, I., Gerber, P.A., Hochuli, M., Kohler, S., Haile, S.R., Gouni-Berthold, I., Berthold, H.K., Spinas, G.A., Berneis, K. (2011). Low to moderate sugar-sweetened beverage consumption impairs glucose and lipid metabolism and promotes inflammation in healthy young men: a randomized controlled trial. The American journal of clinical nutrition, 94:479-485.

13. Beilharz, J., Maniam, J., Morris, M. (2016). Shortterm exposure to a diet high in fat and sugar, or liquid sugar, selectively impairs hippocampaldependent memory, with differential impacts on inflammation. Behavioural brain research, 306:1-7.

14. Lula, E.C., Ribeiro, C.C., Hugo, F.N., Alves, C.M., Silva, A.A. (2014). Added sugars and periodontal disease in young adults: an analysis of NHANES III data-. The American journal of clinical nutrition, 100:1182-1187.

15. Merchant, A.T., Pitiphat, W., Franz, M., Joshipura, K.J. ( W2006). Whole-grain and fiber intakes and periodontitis risk in men-. The American journal of clinical nutrition, 83:1395-1400.

16. Adegboye, A.R., Christensen, L.B., HolmPedersen, P., Avlund, K., Boucher, B.J., Heitmann, B.L. (2012). Intake of dairy products in relation to periodontitis in older Danish adults. Nutrients, 4:1219-1229.

17. Al- Zahrani, M.S. (2006). Increased intake of dairy products is related to lower periodontitis prevalence. Journal of Periodontology, 77:289-294.

18. Bano, A., Afzal, M., Sarwar, H., Waqas, A., Kousar, S., Gulzar, S. (2017). Dietary knowledge, Attitude and Practices of Diabetes Patients at Services Hospital Lahore. International Journal of Applied Sciences and Biotechnology, 5:227-236.

19. Hale, J.L., Householder, B.J., Greene, K.L. (2002). The theory of reasoned action. The persuasion handbook: Developments in theory and practice, 14:259-286.

20. Janz, N.K., Becker, M.H. (1984). The health belief model: A decade later. Health education quarterly, 11:1-47.

21. Topa, G., Moriano, J.A. (2010). Theory of planned behavior and smoking: Meta-analysis and SEM model. Substance abuse and rehabilitation, 1:23-33.

22. Ajzen, I: The theory of planned behavior. (1991). Organizational behavior and human decision processes, 50:179-211.

23. Acheampong, I. (2011). Differences in nutrition knowledge, attitudes and beliefs among low income Hispanic and African American women caretakers. The University of North Carolina at Greensboro. 
24. Acheampong, I., Haldeman, L. (2013). Are nutrition knowledge, attitudes, and beliefs associated with obesity among low-income Hispanic and African American women caretakers? Journal of Obesity, 2013:1-8.

25. Naughton, P., McCarthy, S.N., McCarthy, M.B. (2015). The creation of a healthy eating motivation score and its association with food choice and physical activity in a cross sectional sample of Irish adults. International Journal of Behavioral Nutrition and Physical Activity, 12:74-85.

26. TDoHaC, A. (2018). Texas Bootstrap 2018 Statewide Median Family Income Limits.

27. F.C. (2018). Housing for Austin Communities Housing for Austin.

28. Ajzen, I. (2006). Constructing a theory of planned behavior questionnaire. Amherst, MA.

29. Carmo, C., Ribeiro, M., Teixeira, J., Alves, C., Franco, M., França, A., Benatti, B., Cunha-Cruz, J., Ribeiro, C. (2018). Added Sugar Consumption and Chronic Oral Disease Burden among Adolescents in Brazil. Journal of dental research, 5: 508-514.

30. Yoshihara, A., Watanabe, R., Hanada, N., Miyazaki, H. (2009). A longitudinal study of the relationship between diet intake and dental caries and periodontal disease in elderly Japanese subjects. Gerodontology, 26:130-136.

31. Staudte, H., Kranz, S., Völpel, A., Schütze, J., Sigusch, B.W. (2012). Comparison of nutrient intake between patients with periodontitis and healthy subjects. Quintessence International, 43(10):907-916.

32. Shepherd, R., Sparks, P., Bellier, S., Raats, M: Attitudes and choice of flavoured milks. (1991). extensions of Fishbein and Ajzen's theory of reasoned action. Food quality and preference, 3:157-164.

33. Tsai, T-I., Luck, L., Jefferies, D., Wilkes, L. (2018). A tool to measure the attitudes and beliefs of nursing students towards childhood overweight/obesity. Collegian, 25:341-345.

34. Ostelo, R., Stomp-van den, Berg, S., Vlaeyen, J., Wolters, P., De, Vet, H. (2003). Health care provider's attitudes and beliefs towards chronic low back pain: the development of a questionnaire. Manual therapy, 8:214-222.

35. Drake, T., Ogletree, R.J. (2018). Development of the Health and Weight Attitudes Scale. Journal of nutrition education and behavior, 50:506-510.

36. Steptoe, A., Pollard, T.M., Wardle, J. (1995). Development of a measure of the motives underlying the selection of food: the food choice questionnaire. Appetite, 25:267-284.

37. Bernard, M.E. (1998). Validation of the general attitude and belief scale. Journal of RationalEmotive and Cognitive-Behavior Therapy, 16:183196.

38. Brislin, R.W. (1986). The wording and translation of research instruments.
39. Lula, E.C., Ribeiro, C.C., Hugo, F.N., Alves, C.M., Silva, A.A. (2014). Added sugars and periodontal disease in young adults: an analysis of NHANES III data. The American journal of clinical nutrition, 100:1182-1187.

40. Chapple, I.L., Milward, M.R., Ling- Mountford, N., Weston, P., Carter K., Askey, K., Dallal, G.E., De, Spirt, S., Sies, H., Patel, D. (2012). Adjunctive daily supplementation with encapsulated fruit, vegetable and berry juice powder concentrates and clinical periodontal outcomes: a double- blind RCT. Journal of clinical periodontology, 39:62-72.

41. Pussinen, P.J., Laatikainen, T., Alfthan, G., Asikainen, S., Jousilahti, P. (2003). Periodontitis is associated with a low concentration of vitamin $\mathrm{C}$ in plasma. Clin Diagn Lab Immunol, 10:897-902.

42. Adegboye, A.R., Boucher, B.J., Kongstad, J., Fiehn, N.E., Christensen, L.B., Heitmann, B.L. (2016). Calcium, vitamin D, casein and whey protein intakes and periodontitis among Danish adults. Public health nutrition, 19:503-510.

43. Santos, J.R.A: Cronbach's alpha. (1999). A tool for assessing the reliability of scales. Journal of extension, 37:1-5.

44. Bialocerkowski, A.E., Bragge, P. (2008). Measurement error and reliability testing: Application to rehabilitation. International Journal of Therapy and Rehabilitation, 15:422-427.

45. Tabachnick, B.G., Fidell, L.S., Ullman, J.B. (2007). Using multivariate statistics. Pearson Boston, MA.

46. Williams, B., Onsman, A., Brown, T. (2018). Exploratory factor analysis: A five-step guide for novices. Australasian Journal of Paramedicine, 8(3):1-10.

47. Osborne, J.W., Costello, A.B. (2004). Sample size and subject to item ratio in principal components analysis. Practical assessment, research \& evaluation, 9:8-16.

48. El-Osta, A., Brasacchio, D., Yao, D., Pocai, A., Jones, P.L., Roeder R.G., Cooper, M.E., Brownlee, M. (2008). Transient high glucose causes persistent epigenetic changes and altered gene expression during subsequent normoglycemia. Journal of Experimental Medicine, 205:2409-2417.

49. Geesin, J.C., Darr, D., Kaufman, R., Murad, S., Pinnell, S.R. (1988). Ascorbic acid specifically increases type I and type III procollagen messenger RNA levels in human skin fibroblasts. Journal of Investigative Dermatology, 90:420-424.

50. Nishida, M., Grossi, S.G., Dunford, R.G., Ho, A.W., Trevisan, M., Genco, R.J. (2000). Calcium and the risk for periodontal disease. Journal of periodontology, 71:1057-1066.

51. Hildebolt, C.F. (2005). Effect of vitamin D and calcium on periodontitis. Journal of periodontology, 76:1576-1587.

52. Fishbein, M., Ajzen, I. (1980). Understanding Attitudes and Social Behavior. Prentice Hall, Englewood Cliffs, NJ. 
53. Fishbein, M., Ajzen, I. (1975). Belief, Attitude, Intention and Behavior Reading, MA. AddisonWesley Ford, RC \& Richardson, WD. (1994) Ethical decision making: A review of the empirical literature Journal of Business Ethics, 13:205-221.

54. Mitchell, A.A. (1986). The effect of verbal and visual components of advertisements on brand attitudes and attitude toward the advertisement. Journal of consumer research, 1986, 13:12-24.

55. Mobley, W.H., Griffeth, R.W., Hand, H.H., Meglino, B.M. (1979). Review and conceptual analysis of the employee turnover process. Psychological bulletin, 86:493-501.

56. Naylor, J.C., Ilgen, D.R: Goal setting. (1984). A theoretical analysis of a motivational technology. Research in organizational behavior.

57. Feldman, J.M., Lynch, J.G. (1988). Self-generated validity and other effects of measurement on belief, attitude, intention, and behavior. Journal of applied Psychology, 73:421-432.

58. Boldero, J. (1995). The Prediction of Household Recycling of Newspapers: The Role of Attitudes, Intentions, and Situational Factors 1. Journal of Applied Social Psychology, 25:440-462.
59. A F. (2009). Discovering Statustics Using SPSS. Sage pblication.

60. Messina, F., Saba, A., Vollono, C., Leclercq, C., Piccinelli, R. (2004). Beliefs and attitudes towards the consumption of sugar-free products in a sample of Italian adolescents. European Journal of Clinical Nutrition, 58:420-432.

61. Alvarenga, Md.S, Scagliusi, F.B., Philippi, S.T. (2010). Development and validity of the disordered eating attitude scale (DEAS). Perceptual and motor skills, 110:379-395.

62. de Winter,* J.D., Dodou*, D. I. M. I. T. R. A., \& Wieringa, P. A. (2009). Exploratory factor analysis with small sample sizes. Multivariate behavioral research, 2:147-181.

63. MacCallum RC, Widaman, K. F., Zhang, S., \& Hong, S. (1999) Sample size in factor analysis. Psychological methods, 4:84-96.

64. Schreiber, J.B., Nora, A., Stage, F.K., Barlow, E.A., King, J. (2006). Reporting structural equation modeling and confirmatory factor analysis results: A review. The Journal of educational research, 99:323-338. 